\title{
Ultra fast track surgery: a rapid deployment aortic valve replacement through a J-ministernotomy
}

\author{
Paolo Berretta ${ }^{1}$, Mariano Cefarelli ${ }^{1}$, Walter Vessella ${ }^{2}$, Michele D. Pierri ${ }^{1}$, Roberto Carozza ${ }^{3}$, Giulia \\ Abramucci $^{4}$, Christopher Munch ${ }^{2}$, Hossein M. Zahedi' ${ }^{2}$, Marco Di Eusanio ${ }^{1}$ \\ ${ }^{1}$ Cardiac Surgery Unit, Ospedali Riuniti, Polytechnic University of Marche, Ancona, Italy; ${ }^{2}$ Cardiac Anaesthesia and Intensive Care Unit, ${ }^{3}$ Perfusion \\ Unit, ${ }^{4}$ Preventive Cardiology and Rehabilitation Unit, Ospedali Riuniti, Ancona, Italy \\ Correspondence to: Paolo Berretta, MD. Cardiac Surgery Unit, Cardiovascular Department, Ospedali Riuniti, Polytechnic University of Marche, Via \\ Conca 71, 60126, Ancona, Italy. Email: p.berretta@icloud.com.
}

\begin{abstract}
Aortic valve surgery has been undergone continuous development over the last years, involving less invasive techniques and the use of new technologies to reduce the traumatic impact of the intervention and extend the operability toward increasingly high-risk patients. Minimally invasive aortic valve replacement (AVR) has gradually been recognized as a less traumatic technique compared to median sternotomy, becoming first choice approach in numerous experienced centers. Herein we present our multidisciplinary minimally invasive approach for AVR, involving: (I) reduced chest incision; (II) rapid deployment AVR; (III) minimally invasive extracorporeal circulation system; and (IV) ultra fast track (UFT) anaesthetic management.
\end{abstract}

Keywords: Minimally invasive valve surgery; rapid deployment valve; minimally invasive extracorporeal circulation (MiECC); fast track anaesthesia

Received: 01 March 2018; Accepted: 13 April 2018; Published: 08 May 2018.

doi: 10.21037 /jovs.2018.04.14

View this article at: http://dx.doi.org/10.21037/jovs.2018.04.14

\section{Introduction}

Over the last years, the treatment of patients with severe aortic valve stenosis has been considerably mutated due to the introduction of both minimally invasive aortic valve surgery and transcatheter aortic valve implantation (TAVI) (1). Minimally invasive aortic valve replacement (AVR) has gradually been recognized as a less traumatic technique compared to median sternotomy, becoming first choice approach in numerous experienced centers (1). Aiming to further improve outcomes of patients who require AVR, we have recently established a multidisciplinary minimally invasive approach that involves, in a less invasive way, all the components of the intervention: (I) the surgical incision, through an upper J-ministernotomy; (II) the valve prosthesis, using rapid deployment valve; (III) the cardio-pulmonary bypass (CPB), using minimally invasive extracorporeal circulation (MiECC) system; and (IV) the anaesthetic management, using ultra fast track (UFT) anaesthesia and early (and aggressive) rehabilitation protocol (Figure 1) (3).

The corresponding videos were a case of UFT rapid deployment aortic valve replacement (RD-AVR) through a J-ministernotomy approach.

\section{Clinical vignette}

The patient was a 79-year-old male with severe aortic valve stenosis. He was symptomatic for exertional dyspnea and was classified as New York Heart Association (NYHA) III. Associates comorbidities included hypertension, mild chronic obstructive pulmonary disease and moderate renal insufficiency (creatinine clearance $58 \mathrm{~mL} / \mathrm{min}$ ). The EuroSCORE II was 3.0\%. Transthoracic echocardiogram showed a severe calcific tricuspid aortic valve stenosis associated with mild left ventricular systolic dysfunction [left ventricular ejection fraction $(\mathrm{LVEF})=50 \%]$. Coronary angiography ruled out any significant coronary artery disease. 


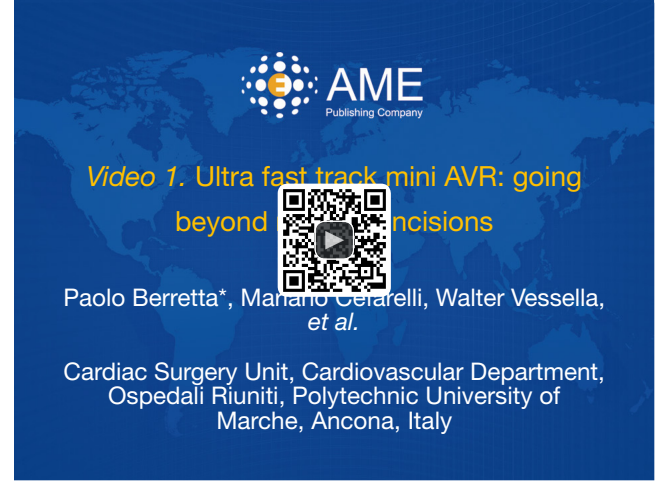

Figure 1 Ultra fast track mini AVR: going beyond reduced incisions (2). AVR, aortic valve replacement.

Available online: http://www.asvide.com/article/view/24671

\section{Surgical technique}

\section{Preparation}

Operative set up was similar to conventional AVR. In addition to basic standard monitoring [ECG 12-leds, invasive blood pressure, central venous pressure, core temperature, $\mathrm{SpO} 2$, end-tidal carbon dioxide (CO2) and urine output] external plaques for direct current (DC) shock were applied. Premedication with morphine $(0.10-0.15 \mathrm{mg} / \mathrm{kg})$ was given 30 minutes before surgery. After induction of anaesthesia using target infusion technology (TCI) system (propofol $2 \%$, remifentanil $50 \mathrm{mcg} / \mathrm{mL}$ ) a short-acting volatile agent (sevoflurane) was used to maintain anaesthesia before and after CPB. Cisatracurium (induction dose: $0.15 \mathrm{mg} / \mathrm{kg}$; maintenance dose: $0.1-0.4 \mathrm{mg} / \mathrm{kg}$ ) were used for neuromuscular block. Transesophageal echocardiography (TEE) probe was set up for the management of MiECC system, detecting any left ventricular distension during cardioplegia delivering or CPB weaning, ensuring complete deairing after aortic declamping and for the evaluation of the prosthesis function.

Prior to skin incision, the jugular notch, the sternal midline (from the angle of Louis to just above the $4^{\text {th }}$ intercostal space), and the xiphoid were marked in order to facilitate surgical incision and accelerate conversion to full sternotomy in case of unexpected complications.

\section{Operation (Figures 2,3)}

The skin incision was started at the sternomanubrial junction and extended $5 \mathrm{~cm}$ inferiorly. A conventional sternal saw was used to perform an upper J-ministernotomy

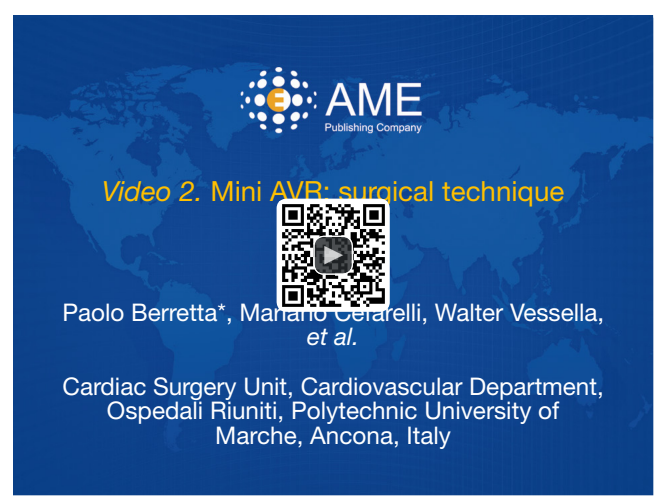

Figure 2 Mini AVR: surgical technique (4). AVR, aortic valve replacement.

Available online: http://www.asvide.com/article/view/24672

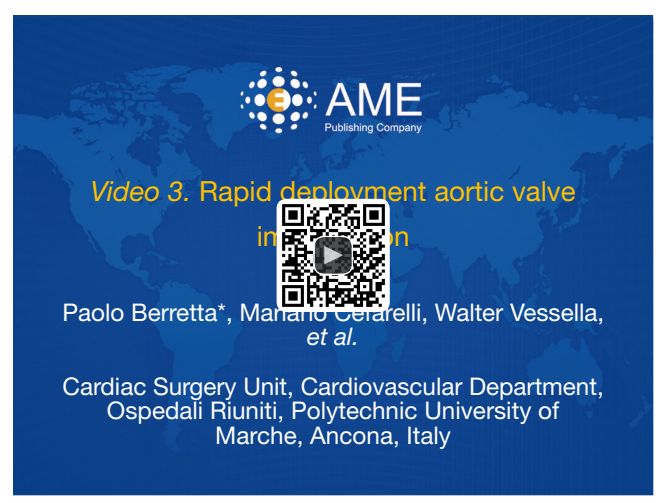

Figure 3 Rapid deployment aortic valve implantation (5). Available online: http://www.asvide.com/article/view/24673

into the $4^{\text {th }}$ intercostal space. A minimally invasive sternal retractor (Ultravision $\mathrm{CT}^{\mathrm{TM}}$ Retractor System, TeDan Surgical Innovations, USA) was placed and opened up progressively to avoid sternal and costal fractures, and to decrease postoperative pain. The pericardium was opened longitudinally from the innominate vein to the lowest point visible caudally, and the surgical field was exposed using 6 pericardial stay sutures. The individual patient's response to heparin was estimated with the Hepcon/ HMS system (Medtronic Inc, Minneapolis, USA), and systemic heparinization was achieved using a low-dose anticoagulation protocol with a targeted activated clotting time of 300-350. Minimally invasive CPB (ROCSafe ${ }^{\mathrm{TM}}$ Hybrid Perfusion System, Terumo, USA) was instituted by means of standard central cannulation. Two 3-0 polyester purse string sutures for the aortic cannula are placed in the 


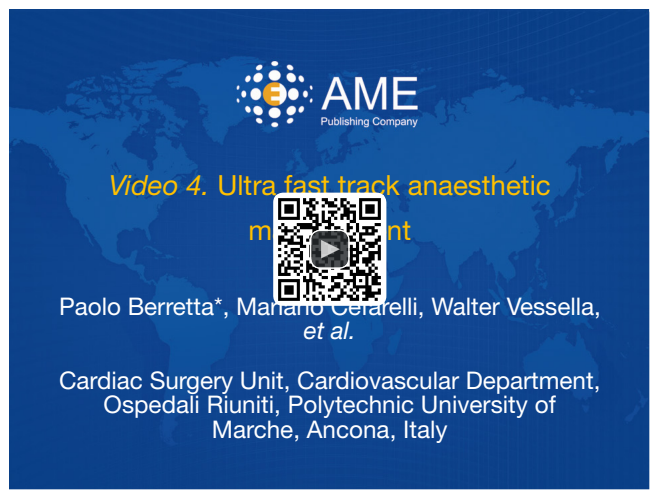

Figure 4 Ultra fast track anaesthetic management (6). Available online: http://www.asvide.com/article/view/24674

distal ascending aorta by applying downward traction via an Adson clamp placed on the aortic adventitia, to improve exposure and facilitate cannulation manoeuvres. The aorta is carefully cannulated using a low profile cannula with a longer body $\left(\mathrm{EOPA}^{\mathrm{TM}}\right.$ Arterial Cannula, Medtronic Inc, USA) that allows for an easy insertion from a distance and provides an unencumbered operative field. A 4-0 polypropylene pledgeted purse string suture was placed to the right atrium cannulation site $\left(32 / 40 \mathrm{Fr} . \mathrm{Mc}^{\circledR}\right.$ venous cannula, Medtronic Inc, USA) in order to minimize air leakage. For reducing hemodilution, the MiECC circuit was retrogradely primed with patient's blood, placing the operating table in Trendelenburg position to increase venous return. Left ventricular venting was achieved via the right upper pulmonary vein $\left(\mathrm{DLP}^{\circledR}\right.$ vent cannula, Medtronic Inc, USA) into a coated flexible reservoir provided with filter screen. The MiECC setup included a cell saving device (Dideco Electa, Sorin Group, Italy) to process and transfuse blood during the operation. After normothermic CPB institution, with an empty heart, a $19 \mathrm{Fr}$ subxiphoid spiral drain was placed, to continuously inflate $\mathrm{CO}_{2}$ into the pericardial cavity. The same drain was used as a pericardial drain at the end of the procedure. Under a low-flow condition, an atraumatic minimally invasive clamp (Cygnet ${ }^{\circledR}$ Flexible Clamps, Vitalitec, USA) was applied across the distal ascending aorta, and warm blood cardioplegia was given in antegrade fashion, through the aortic root (Figure 2).

A "hockey-stick" aortotomy crossing the sinotubular junction was performed and the aortic valve was exposed. The aortic cusps were removed and the annulus decalcified. Excessive debridement of annular calcification should be avoided in order to prevent large annular defects. The aortic annulus was measured and a $21 \mathrm{~mm}$ Intuity Elite ${ }^{\mathrm{TM}}$ rapid deployment valve was selected. Meanwhile, the Intuity Elite ${ }^{\mathrm{TM}}$ valve was washed in saline solution and then loaded onto the delivery system, three braided guiding sutures were placed at the nadir of each coronary cusp. These sutures were then passed through the sewing ring of the Intuity Elite $^{\mathrm{TM}}$ valve at the black markers. The valve was lowered into the aortic annulus, and the three sutures were snared with a tourniquet, making sure that the aortic side of each annular stich was clearly visible over the sewing ring of the prosthesis. Once the valve was properly seated in the aortic annulus, the stent was expanded within the left ventricular outflow tract by inflating the balloon catheter with sterile water to $4.5 \mathrm{~atm}$ for 10 seconds. After balloon deflation, the snares and the delivery system were removed, proper seating of the valve was checked, and the three guiding sutures were tied (Figure 3).

\section{Completion (Figure 4)}

The aortotomy was closed in the usual fashion. Before releasing the aortic clamp, two pacing wire electrodes were sutured to the right ventricle, the operating table was tilted, with the patient's head down, and $\mathrm{CO}_{2}$ insufflation was discontinued. The left ventricle was meticulously deaired by filling the heart and gently inflating the lungs. Perfusion flow rate was temporarily diminished as the aortic clamp was released. TEE was performed to prevent left ventricular overdistension and assess adequate deairing and valve function. $\mathrm{CPB}$ was weaned off and protamine was administered to contrast heparinization, as estimated with the Hepcon/HMS system. Total CPB and myocardial ischemic time was 50 and 38 minutes, respectively. Following venous decannulation, the blood in the MiECC circuit was completely re-transfused through antegrade washout by replacing it with a crystalloid solution in order to minimize blood loss. Once the haemostasis was satisfactory, the pericardium was closed above the ascending aorta and the sternum was closed with four single steel wires. Absorbable sutures were used for closing subcutaneous tissue and skin.

Few minutes before surgery completion, the inhalational agent was stopped and alveolar recruitment was achieved using a temporary $10 \mathrm{cmH} 2 \mathrm{O}$ positive end-expiratory pressure. Local anaesthetic infiltration (ropivacaine $10 \mathrm{~mL}$ + lidocaine $10 \mathrm{~mL}$ ) of suture and drains sites was used for immediate postoperative pain relief. At the end of surgery, the neuromuscular blockade was reversed with Sugammadex 
$(2-4 \mathrm{mg} / \mathrm{kg})$ and the patient was extubated in the operating room (Figure 4).

\section{Postoperative course (Figure 4)}

The patient was transferred to the intensive care unit (ICU) with 50\% FiO2 oxygen supplementation through a facemask. Postoperative analgesia was provided with Tramadol (4-8 $\mathrm{mcg} / \mathrm{kg} / \mathrm{min}$ ) for $24 \mathrm{~h}$. Respiratory and mobilization rehabilitation therapy was started 2 hours after surgery in the ICU, with breathing exercises, and active upper and lower limb movements. The patient was then transferred to the sub-ICU, six hours after the operation. The morning after, the drains were removed (total blood loss: $120 \mathrm{cc}$ ) and oral feeding was started. During the first post-operative day the patients was transferred to the ward and received 2 treatment sessions by the physiotherapists involving bad and chair sitting, standing and ambulation as well as breathing exercises. In addition, the physiotherapists instructed the patients to perform breathing exercises on a regular basis. During the hospitalization no transfusions were required, and the patient was uneventfully discharged five days after the operation (Figure 4).

\section{Indications and contraindications}

All adult patients with severe aortic valve pathology who require AVR (7) are eligible for UFT mini RD-AVR intervention. Our exclusion criteria have been previously reported (3). Briefly, they involve (I) urgent and emergency surgery; (II) previous cardiac surgery; (III) severe chest wall deformities; (IV) infective endocarditis; (V) concomitant procedures; (VI) severe hemodynamic instability; (VII) severe heart failure; (VIII) severe renal failure or hepatic disease; (IX) bleeding >100 cc/hour; (X) prolonged CPB time (>120 min); (XI) hypothermia; (XII) severe pulmonary hypertension; and (XIII) history of stroke or major neurologic dysfunction.

\section{Discussion}

Minimally invasive aortic valve surgery has been increasingly accepted in the surgical community as a valid alternative to conventional full sternotomy, with benefits of decreased hospitalization, faster functional recovery, less blood transfusion, reduced renal and wound complications, and decreased hospital costs. However, current evidence shows that mini AVR is similar, and not superior, to conventional
AVR in terms of survival and other major clinical endpoints (8-12). In fact, the advantages of minimally invasive approach may be offset by the increased technical difficulty and the extended duration of CPB and cross-clamp times that result when operating through narrow working spaces. However, the concept of minimally invasive AVR should be broader than simply reducing the length of the surgical incision. In fact, by implementing the reduced incision with the latest technological advancements allowing for mitigating the disparities in operative times and improving valve hemodynamics (RD-AVR) (13-16), and reducing the deleterious effects of CPB (MiECC system) (17), the patient's global trauma may be further decreased leading to superior clinical outcomes. Furthermore, patients undergoing mini RD-AVR using MiECC system, may represent a very appealing cohort for UFT anaesthesia concepts. UFT management combined with the advanced surgical and perfusion techniques may help promote early recovery and further reduce postoperative complications $(18,19)$, particularly in elderly and high risk patients.

\section{Conclusions}

UFT mini RD-AVR is a multidisciplinary minimally invasive approach that involves the latest best technologies and techniques for aortic valve surgery. We believe it may be associated with increased patient's comfort, faster recovery and, most importantly, translate into superior clinical outcomes compared to standard AVR. However, further studies to adequately assess early and late clinical outcomes are warranted, in this setting.

\section{Acknowledgements}

None.

\section{Footnote}

Conflicts of Interest: The authors have no conflicts of interest to declare.

Informed Consent: Written informed consent was obtained from the patient for publication of this manuscript and any accompanying images.

\section{References}

1. Nguyen TC, Terwelp MD, Thourani VH, et al, Clinical 
trends in surgical, minimally invasive and transcatheter aortic valve replacement†. Eur J Cardiothorac Surg 2017;51:1086-92.

2. Berretta P, Cefarelli M, Vessella W, et al. Ultra fast track mini AVR: going beyond reduced incisions. Asvide 2018;5:502. Available online: http://www.asvide.com/ article/view/24671

3. Di Eusanio M, Vessella W, Carozza R, et al. Ultra fasttrack minimally invasive aortic valve replacement: going beyond reduced incisions. Eur J Cardiothorac Surg 2018. [Epub ahead of print].

4. Berretta P, Cefarelli M, Vessella W, et al. Mini AVR: surgical technique. Asvide 2018;5:503. Available online: http://www.asvide.com/article/view/24672

5. Berretta P, Cefarelli M, Vessella W, et al. Rapid deployment aortic valve implantation. Asvide 2018;5:504. Available online: http://www.asvide.com/article/ view/24673

6. Berretta P, Cefarelli $M$, Vessella $W$, et al. Ultra fast track anaesthetic management. Asvide 2018;5:505. Available online: http://www.asvide.com/article/view/24674

7. Baumgartner H, Falk V, Bax JJ, et al. 2017 ESC/EACTS Guidelines for the management of valvular heart disease: The Task Force for the Management of Valvular Heart Disease of the European Society of Cardiology (ESC) and the European Association for Cardio-Thoracic Surgery (EACTS). Eur Heart J 2017;38:2739-91.

8. Phan K, Xie A, Di Eusanio M, et al. A meta-analysis of minimally invasive versus conventional sternotomy for aortic valve replacement. Ann Thorac Surg 2014;98:1499-511.

9. Ghanta RK, Lapar DJ, Kern JA, et al. Minimally invasive aortic valve replacement provides equivalent outcomes at reduced cost compared with conventional aortic valve replacement: A real-world multi-institutional analysis. J Thorac Cardiovasc Surg 2015;149:1060-5.

10. Kirmani BH, Jones SG, Malaisrie SC, et al. Limited versus full sternotomy for aortic valve replacement. Cochrane Database Syst Rev 2017;4:CD011793.

11. Lim JY, Deo SV, Altarabsheh SE, et al. Conventional

doi: 10.21037 /jovs.2018.04.14

Cite this article as: Berretta $\mathrm{P}$, Cefarelli M, Vessella W, Pierri MD, Carozza R, Abramucci G, Munch C, Zahedi HM, Di Eusanio M. Ultra fast track surgery: a rapid deployment aortic valve replacement through a J-ministernotomy. J Vis Surg 2018;4:90. versus minimally invasive aortic valve replacement: pooled analysis of propensity-matched data. J Card Surg 2015;30:125-34.

12. Brown ML, McKellar SH, Sundt TM, et al. Ministernotomy versus conventional sternotomy for aortic valve replacement: a systematic review and meta-analysis. J Thorac Cardiovasc Surg 2009;137:670-679.e5.

13. Borger MA, Dohmen PM, Knosalla C, et al. Haemodynamic benefits of rapid deployment aortic valve replacement via a minimally invasive approach: 1 -year results of a prospective multicentre randomized controlled trial. Eur J Cardiothorac Surg 2016;50:713-20.

14. Andreas M, Wallner S, Habertheuer A, et al. Conventional versus rapid-deployment aortic valve replacement: a singlecentre comparison between the Edwards Magna valve and its rapid-deployment successor $†$. Interact Cardiovasc Thorac Surg 2016;22:799-805.

15. Barnhart GR, Accola KD, Grossi EA, et al. TRANSFORM (Multicenter Experience With Rapid Deployment Edwards INTUITY Valve System for Aortic Valve Replacement) US clinical trial: Performance of a rapid deployment aortic valve. J Thorac Cardiovasc Surg 2017;153:241-251.e2.

16. Phan K, Tsai YC, Niranjan N, et al. Sutureless aortic valve replacement: a systematic review and meta-analysis. Ann Cardiothorac Surg 2015;4:100-11.

17. Anastasiadis K, Murkin J, Antonitsis P, et al. Use of minimal invasive extracorporeal circulation in cardiac surgery: principles, definitions and potential benefits. A position paper from the Minimal invasive Extra-Corporeal Technologies international Society (MiECTiS). Interact Cardiovasc Thorac Surg 2016;22:647-62.

18. Gutsche JT, Erickson L, Ghadimi K, et al. Advancing extubation time for cardiac surgery patients using lean work design. J Cardiothorac Vasc Anesth 2014;28:1490-6.

19. van Mastrigt GA, Maessen JG, Heijmans J, et al. Does fast-track treatment lead to a decrease of intensive care unit and hospital length of stay in coronary artery bypass patients? A meta-regression of randomized clinical trials. Crit Care Med 2006;34:1624-34. 